\title{
SSinteza
}

Impact of Internet on Business Activities

\section{ORGANIZACIONA SOCIJALIZACIJA KAO INTEGRATIVNI FAKTOR ORGANIZACIONE KULTURE}

\author{
Boško Ivanović ${ }^{1}$, Božidarka Arsenović ${ }^{2}$ \\ ${ }^{1}$ „Orao“ a.d., Bijeljina, Šabačkih đaka bb, Bijeljina, Republika Srpska \\ ${ }^{2}$ Ekološki fakultet, Nezavisni univerzitet Banja Luka, Republika Srpska
}

\begin{abstract}
:
U uslovima globalizacije tržišta, problemi sa kojima se organizacije susreću, sve su složenija. U borbi za konkurentnost, organizaciona kultura se javlja kao važan faktor uspješnosti organizacije. Naime, korporativna kultura se vezuje za sve izraženije zahtjeve u smislu povećanja radne efikasnosti; za definisanje novih radnih vrijednosti, jer je primjetna tendencija nepoštovanja normi u procesu rada (posebno u razvijenim industrijskim zemljama koje su svoja načela vezivala za protestantsku etiku); vezuje se za pojavu gubljenja smisla u svijetu rada, gdje su hedonističke vrijednosti u velikoj ekspanziji, ali i za socijalnu dezintegraciju i dezorjentaciju. Jedan od uslova za bolje poslovanje je i sposobnost menadžera da unaprijede kulturu u organizaciji. Prema brojnim autorima socijalizacija je dobar način kako da to ostvarimo.
\end{abstract}

\author{
Key words: \\ organizaciona kultura, \\ organizaciono ponašanje; \\ organizaciona socijalizacija.
}

\section{UVOD}

Oraganizaciona (korporativna) kultura je jedna od ključnih varijabli organizacionog ponašanja. Sa strategijom i vođenjem (leadership), organizaciona kultura čini okosnicu poslovnog uspjeha. Organizaciona kultura je bazična dimenzija organizacione sredine, koja određuje organizacionu situaciju.

U zavisnosti od filozofije organizacije, kultura organizacije se manifestuje kroz etičke vrijednosti i norme koje zaposlene obavezuju da ih prihvate i da se ponašaju u skladu sa time. Ove norme se reflektuju u identitetu organizacije u smislu kreiranja unutrašnje predstave o svom bitisanju i predstavljanju u odnosu na okruženje. Prema tome, korporativna kultura je specifičan skup zajedničkih vjerovanja, stavova, vrijednosti, osnovnih načela i normi u jednoj kompaniji, koji oblikuju njen identitet i ostvaruju pretpostavke međusobnog djelovanja i aktivnosti, kao što determinišu način rada, poslovanja i ponašanja [2].

Prema Koteru i Hesketu, kultura ima sve značajniji i sve veći uticaj na učinak organizacije. U tom smislu, iznijeli su svoje zaključke [3]:

- korporativna kultura može da ima značajan uticaj na ekonomski učinak organizacije,

- korporativna kultura će najvjerovatnije biti još važniji faktor u određivanju uspjeha ili neuspjeha organizacije u budućnosti,

- korporativne kulture koje koče izrazit finansijski učinak nisu rijetke, takve kulture se lako razvijaju, čak i u onim organizacijama u kojima ima razumnih i inteligentih ljudi,
- korporativne kulture se teško mijenjaju, ali se mogu modifikovati u cilju povećanja učinka.

Pri kreiranju i uobličavanju kulture organizacije utiču različiti faktori spoljašnjeg okruženja. Važnu ulogu ima ekonomski sistem u kome organizacija egzistira, što znači da je takav sistem moderan, racionalan, stimulativan i konkurentski orjentisan. Bitan je i nivo razvijenosti tržišta sa svim obilježjima i karakteristikima tržišne konkurencije. Kako će izgledati korporativna kultura uticaj imaju i socijalni faktori, posebno tehnoške inovacije, naučna dostignuća, kao i sam politički sistem. Na korporativnu kulturu utiču i neki unutrašnji faktori, kao što su svrha, strategija i tehnologija organizacije i moguće krize u kojoj organizacija posluje.

Ipak, najznačajniji faktor koji utiče na formiranje kulture organizacije je lična filozofija i ponašanje rukovodstva, jer od stila rukovođenja i upravljačke strukture zavisi specifičnost kulture organizacije. Rukovodioci su ti koji svojom moći odlučivanja i nametanja obrazaca drugima oblikuju modele ponašanja. Na oblikovanje standarda ponašanja u organizaciji, pored spoljašnjih faktora, utiču i lične osobine vlasnika ili glavnih menadžera.

Organizaciona kultura ima bitnu ulogu u uspješnosti organizacije na koju djeluju različiti činioci, kao što to pokazuje sl. 1 [4].

Sa sl. 1 vidimo da se organizaciona kultura javlja kao transmisija interpolirana između činilaca okoline i uspješnosti organizacije. Pod uticajem različitih činilaca okruženja oblikuje se odgovarajuća organizaciona kultura koja jako utiče na uspješnost organizacije. Uspešnost, sa svoje strane, povratno djeluje na organizacionu kulturu i tako se one uzajamno potpomažu. 


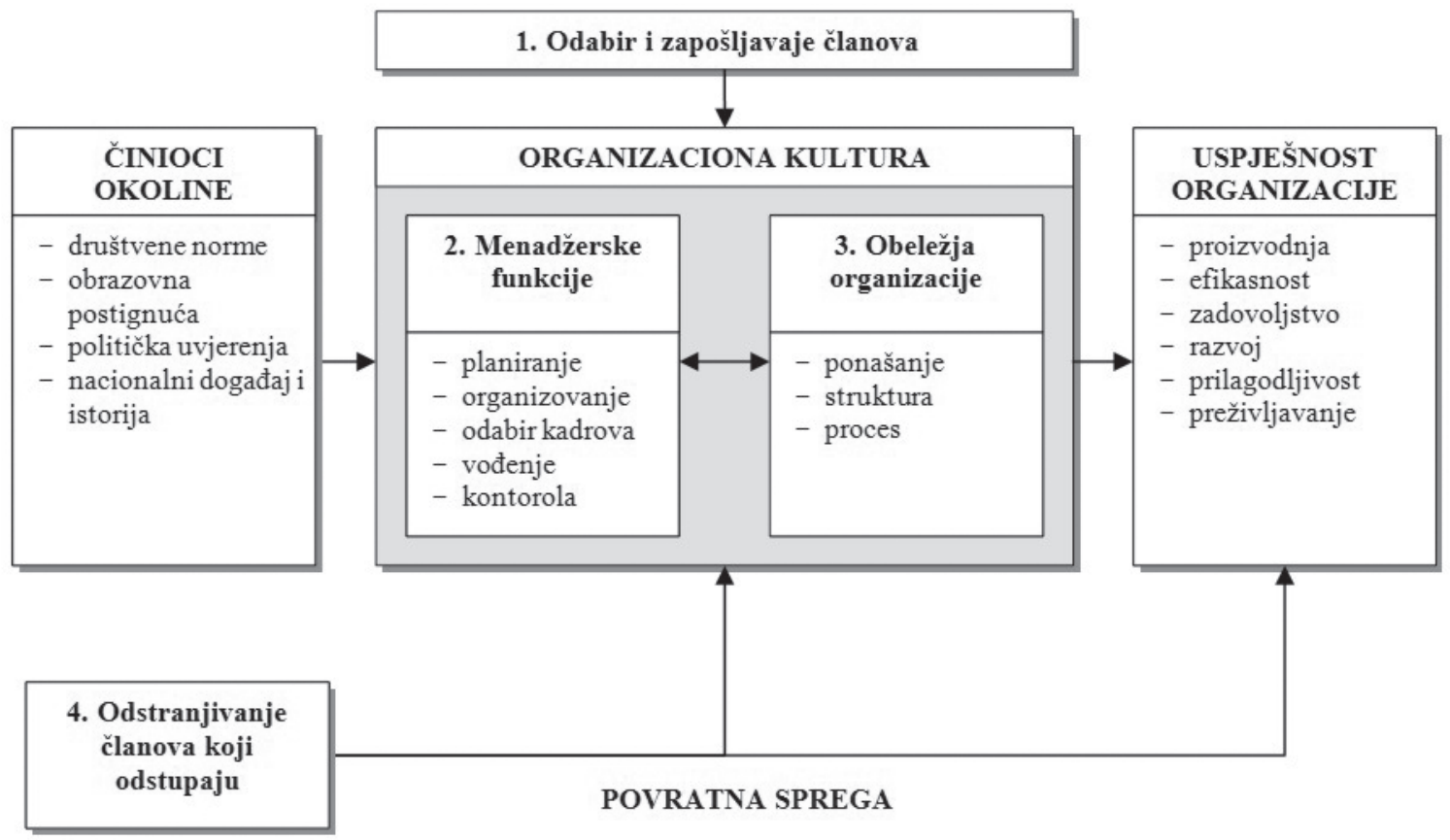

Sl. 1. Organizaciona kultura i uspješnost organizacije

\section{ORGANIZACIONO PONAŠANJE I VRSTE ORGANIZACIONIH KULTURA}

Organizaciono ponašanje (organizational behaviour) je oblast koja izučava ponašanje ljudi u organizacionoj sredini. U praktičnom smislu, ova oblast je nova upravljačka aktivnost koja se sastoji u oblikovanju ponašanja ljudi u organizacijama. Formiranje ponašanja ljudi u organizacijama je upravljačka aktivnost koja je u nadležnosti menadžera. Menadžeri, oblikujući ponašanje ljudi u organizaciji utiču na razvoj i promjene ličnih karakteristika i/ ili na promjene organizacionog konteksta.

Pristup organizacionom ponašanju nudi dvije perspektive i tri nivoa analize.

1. Prva perspektiva je iz ugla pojedinca u organizaciji i ima za cilj da upozna pojedinca sa karakteristikama i problemima ponašanja, da ga osposobi da razumije svoje i tuđe ponašanje.

2. Druga perspektiva je iz ugla rukovodioca i ima za cilj da osposobi rukovodioca za razumijevanje ponašanja zaposlenih sa kojima radi, sarađuje i upravlja.
Ponašanje zaposlenih se analizira na tri nivoa:

- Individualnom (fokus je na pojedincu),

- Grupnom (fokus je na grupama, intra i intergrupnim odnosima) $i$

- Organizacionom (fokus je na cjelini organizacije).

Prema Džonu Koteru (John Kotter) i Džejmsu Hesketu (James Heskett) postoje dva nivoa kulture [6]:

1. Prvi nivo, nevidljivi, čine vrednosne orjentacije koje poštuju svi zaposleni, one se prenose kao tradicija, pa tako ostaju nepromjenjene.

2. Drugi nivo, vidljivi, odnosi se na norme grupnog ponašanja izražene u vidu uobičajenih i vladajućih modela ponašanja.

Analizom uticaja pojedinih elemenata kulture na upravljanje bavili su se tu mnogi istraživači i teoretičari kulture. Ipak, najznačajniji doprinos dao je Girt Hofstejd (G. Hofstede), holandski istraživač. Iz svojih istraživanja koja su obuhvatila oko sto hiljada ljudi u četrdeset zemalja, proizašao je rezultat, a odnosio se na četiri glavne dimenzije koje bi mogle da čine bilo koju nacionalnu kulturu [7].

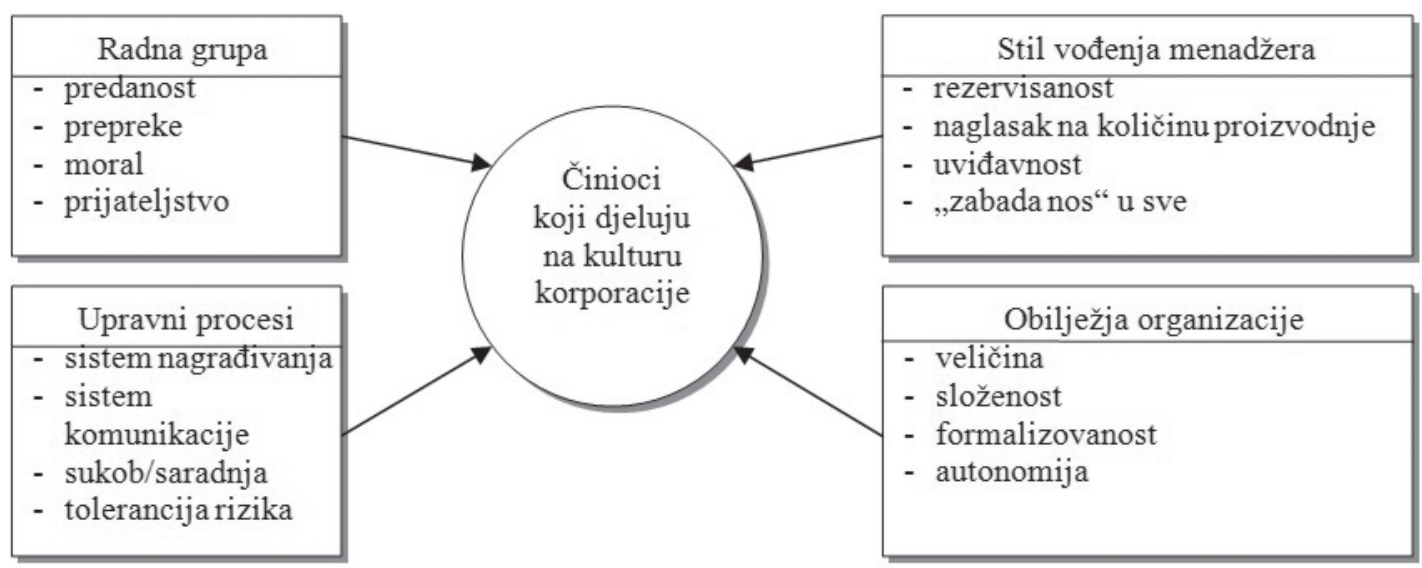

Sl. 2. Činioci koji djeluju na kulturu korporacije 
Individualizam podrazumeva respekt samo sopstvenih interesa, a kolekivizam respektuje i posvećuje pažnju kolektivnim interesima i celokupnim društvenim odnosima u okviru jedne grupe.

Distanca snage, tj. moći podrazumeva podelu moći, pa ako je ta distanca moći veća očekuje se neravnopravna raspodela moći instiucija, organizacija, grupa i pojedinaca.

Izbegavanje neizvesnosti podrazumeva stepen tolerancije i prema riziku i prema nekonvencionalnom ponašanju, pa u tom smislu visok stepen izbegavanja neizvesnosti se odnosi na one kulture u kojima se oseća neprijatnost pri susretu sa neizvesnim situacijama, tako da su to kulture koje temelje na osnovama sigurnosti i izvesnosti, dok je situacija sa niskm nivoom izbegavanja neizvesnosti i stepen tolerancije prema riziku i nekonvencionalnom ponašanju je suporotna.

Kvantitativan prema kvalitativnom stilu života, u smislu definisanja takozvanih muških i ženskih vrednosti, pa se kvantitet vezuje za materijalna dobra otelotvorena $\mathrm{u}$ novcu, koja utiču na nivo agresivnosti u njihovom sticanju i odnose se na tzv. muške vrednosti. Međutim, pod kvalitativnim silom života podrazumeva orjentacija ka duhovnoj vrednosti i odnosima među ljudima, pa se ovaj stil bazira na tzv. ženskim vrednostima.

Nešto posle, Hofstejd je zajedno sa Majklom Bondom (M. Bond), utvrdio i petu dimenziju nacionalne kulture koja se odnosi na vremensku dimenziju, tj. nivo jedne nacionalne zajednice prema kratkoročnim ili dugoročnoj orijentaciji [8].

Jedno od bitnih pitanja tiče se činilaca koji djeluju na kulturu korporacije. Postoje brojni činioci koji djeluju na organizaciju, među kojima specijalno mjesto pripada odnosima u radnoj grupi, stilu vođenja menadžera, obilježjima organizacije kao procesima upravljanja koji egzistiraju u organizaciji, sl. 2 [4].

Svaka organizacija ima svoju organizacionu strukturu, pa time i odgovarajuću organizacionu kulturu. Razlikujemo sljedeće vrste organizacionih kultura [4]:

- dominantnu kulturu i subkulturu,

- jaku i slabu kulturu,
- jasnu i nejasnu kulturu,

- odličnu (izvrsnu) i užasnu kulturu,

- postojanu i prilagodljivu i

- participativnu i neparticipativnu kulturu.

Svaka organizacija bi trebalo da ima prepoznatliivu dominantnu kulturu, što ne mora biti u koliziji sa postojanjem i većeg broja subkultura. Odnos subkultura prema dominantnoj kulturi trebao bi biti kao odnos podskupa prema skupu. Položaj subkultura u organizacionoj strukturi prikazan je na sl. 3 [4].

Podjela na jaku i slabu kulturu bazira se na činjenici da li u organizaciji postoji konsenzus, sporazum tj. široko raspostranjeno jedinstvo oko nekih zajedničkih vrijednosti. Ako je riječ o jakoj kulturi, to jedinstvo egzistira, u protivnom, radi se o slaboj kulturi (ako je malo zajedništva oko specifičnih vrijednosti).

Kultura može biti jasna i nejasna. One kulture koje su po nekim svojim simbolima, prepoznatljive za članove organizacije (kao i za ljude van organizacije) predstavljaju jasne kulture. Svakako da nejasne kulture nije lako prepoznati. To su one kulture za koje mnogi zaposleni, pa i dobar dio menadžmenta, nije u stanju da odgovori šta je i kakva je njihova kultura organizacije.

Organizaciona kultura može biti odlična (izvrsna) $i$ užasna. U organizacijama sa izvrsnom kulturom postoji određeni red koji doprinosi toj izvrsnosti. U takvoj organizaciji poklanja se velika pažnja razvoju komunikacija između zaposlenih i menadžmenta, izvrsna kultura predstavlja način planiranog života organizacije. Onaj ko radi u takvoj organizaciji osjeća se kao član porodice. U toj organizaciji planiranje je standardna metoda koja se koristi na svim nivoima organizacije. Suprotnost izvrsnoj kulturi je njen antipod užasna kultura. Užasne kulture uglavnom su prepoznatljive po kriznom menadžmentu, po konstantnoj i velikoj zbrci, po „žarištima“ koji se ne mogu ugasiti. U ovakvim organizacijama klima je, za većinu zaposlenih, neprijatna i frustrirajuća.

Organizacije koja funkcionišu u stabilnoj okolini imaće postojanu (konstantnu) kulturu, dok kod organizacija koja egzistiraju u veoma promjenljivoj (turbulentnoj) okolini imaće prilagodljivu (adaptilnu, promenljivu) kulturu. Za razliku od postojane kulture koja ima teži-

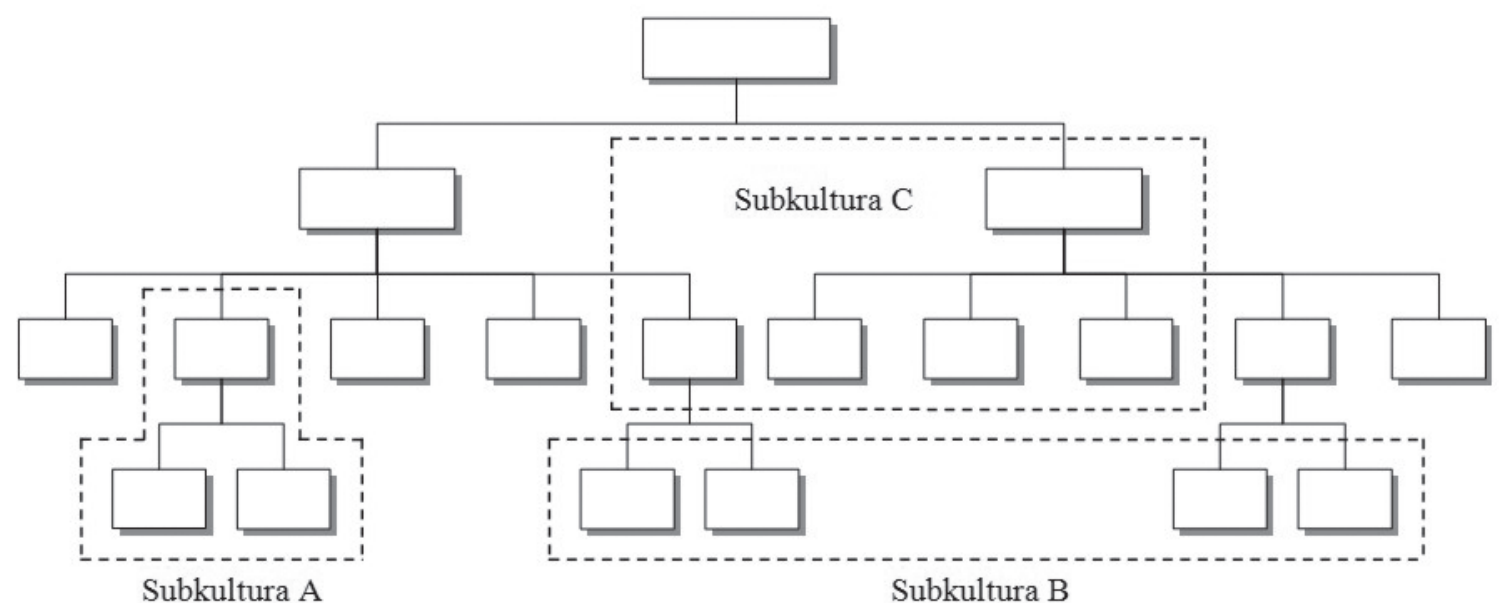


šte na unutrašnjim činiocima organizacije, promjenljiva kultura je orjentisana na spoljašnju okolinu. Zbog brzih promjena u okolini promjenljiva kultura se prilagođava potrebama kupaca.

Kultura može biti participativna i neparticipativna. Ako su zaposleni u organizaciji, u dovoljnoj mjeri uključeni u proces odlučivanja, tada govorimo o participativnoj kulturi i obrnuto, tamo gdje odluke donosi samo menadžment bez konsultacija sa svojim saradnicima, govorimo o neparticipativnoj kulturi.

Iz prethodno navedenih vrsta organizacionih kultura, proizlazi da kultura bitno opredjeljuje koheziju ili čak raspad organizacije, sl. 4 [4].

Ukoliko je organizaciona kultura jedinstvena to će snažno homogenizovati organizaciju, nasuprot potpuno nepovezanoj i neprepoznatljivoj, nejasnoj i različitoj kulturi organizacije koja će dovesti do raspada organizacije.

\section{ORGANIZACIONA SOCIJALIZACIJA}

Proces socijalizacije je nadgradnja uticaja porodice na ličnost. Ipak, socijalizacija ne može u potpunosti da izmijeni karakteristike ličnosti koje su formirane u porodici. Veliki broj autora smatra da je socijalizacija najbolji metod organizacionog ponašanja. Ona, sama po sebi - pruža odgovore zašto se zaposleni ponašaju na određeni način u organizaciji [1].

Jedan od uslova za bolje poslovanje je i menadžerska sposobnost razvoja kulture grupe u organizaciji. Na primjer, treba stvarati sektore sastavljenih od ljudi iste starosti, zatim od ljudi sličnog obrazovanja i od ljudi koji imaju ista interesovanja, iste želje i ambicije. Nije slučajno da japanske kompanije „regrutuju“ službenike - još iz srednje škole, koji istovremeno dolaze u organizaciju poslije završenog fakulteta, zajedno napreduju na poslu, itd. [1]

Primjer br. 1 [1]:

Vozeći se, u maju 1989. godine, čuvenim super-brzim vozom „Šinkansen" (Shinkansen) iz grada Okajame (Okayama) u Tokio (Tokyo), upoznao sam mlađeg čovjeka, koji je, vidjevši da sam stranac, počeo razgovor, sa namjerom da prekrati vrijeme putovanja. Na moje pitanje, šta je po zanimanju, odgovorio je : „Radim za Takizavu“. Jednom drugom prilikom krenuo sam vozom sa Londonske Viktorije za Epsom. Ljudi su se vraćali sa posla kućama. Veoma mlad čovjek, u klasičnom sivom odijelu i sa kravatom sa kosim prugama, ponosno mi je rekao: „Ja sam inženjer informatike i diplomirao sam na Kraljevskom koledžu za tehnologiju (Imperial College of Technology)“. Nije mi rekao za koju kompaniju radi.

Razvoj kulture pojedinca i grupa, kreiranje „imidža“ organizacije, odnosno - idenifikacija radnika sa istim i njihova velika integrisanost u organizaciju, značajan su činilac dobrog organizacionog ponašanja. Iz prethodnog primjera vidi se da je „posljedica“ visokog stepena organizacione kulture japanskog radnika, njegova totalna identifikacija sa organizacijom za koju radi. S druge strane, zapadna organizaciona struktura ima karakteristiku isticanja individualnog nad kolekivnim; drugim riječima - nije na tako visokom nivou [1].

Jedan od ključnih zadataka je da rukovodioci shvate socijalizaciju zaposlenih i da velika odgovornost, u tom smislu, leži na njima. Socijalizacija novopridošlih (pripravnika) obuhvata prihvatanje novih normi, vrijednosti i oblika ponašanja koji su od prije prihvaćeni od strane ostalih članova organizacije.

Karakteristike organizacione socijalizacije su [1]:

1. Promjena stavova, vrijednosti i ponašanja.

2. Proces koji traje.

3. Prilagođavanje novom poslu, grupi i cjelokupnoj organizaciji.

4. Međusobni uticaj novodošlih radnika i menadžera.

5. Kritički stavovi u ranoj fazi socijalizacije.

Koliko je važna organizaciona socijalizacija za svaku organizaciju, najbolji nam primjer pokazuje pristup Japanaca ovom problemu. Kada se u japansku kompaniju prime novi ljudi, mladi i bez velikog iskustva, svakome od njih se dodjeluje, nazovimo ga - mentor. To je po običaju, stariji, iskusniji radnik, koji se brine da mladi kolega što bolje (u potpunosti) uključi u rad kompanije. Naravno, to je u skladu sa konfucijanskim učenjem, koje je veoma prisutno u organizacijijama japanskih kompanija. Zaista, stariji radnik upoznaje mlađeg o istoriji kompanije, kao i sa ostalim radnicima (službenicima). Isto tako, oni prolaze sve radne pozicije, raspravljaju o mogućim problemima i novim idejama. I preko toga, oni se druže i poslije radnog vremena, idu zajedno na fudbalske utakmice i u tradicionalna japanska kupatila, gdje - u opuštenoj atmosferi - razmatraju probleme kompanije i pokušavaju da se - obojica - sažive sa njima. Ovakav način organizacione socijalizacije dao je najbolje rezultate u Japanu.

Različiti načini socijalizacije primjenjuju se, sa manjeviše uspjeha, u većini velikih svjetskih kompanija. Ipak, proces socijalizacije ne mora uvijek da dobro funkcioniše.

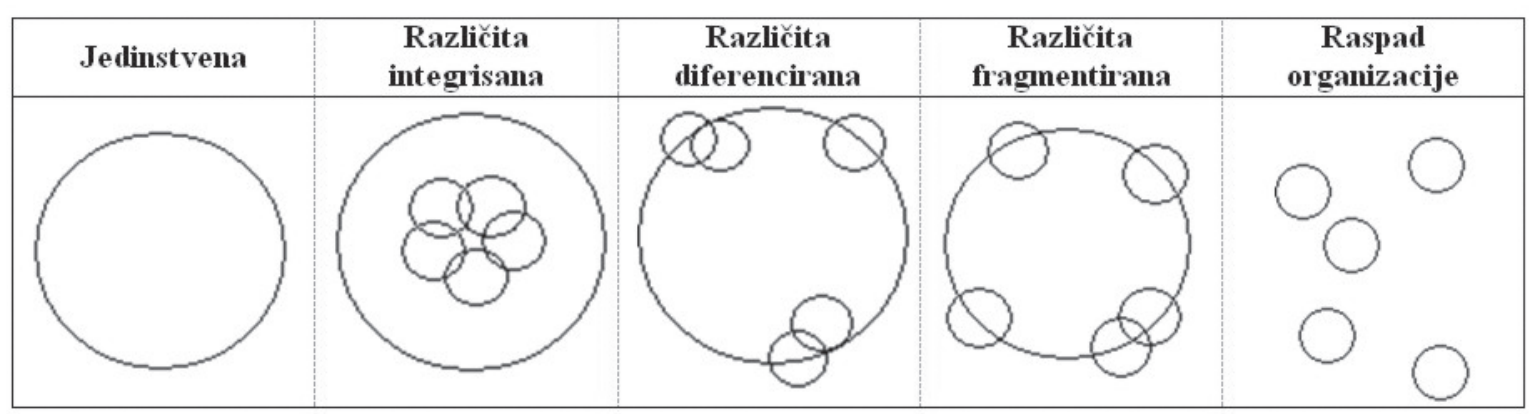

Sl. 4. Različiti nivoi integrisanosti organizacione kulture korporacije 
To se ponekad dešava i na najvišim pozicijama u kompaniji - usljed različitih tipova ličnosti top menadžera.

Primjer br. 2 [1]:

Kada je Dženeral motors (GM) počeo da gubi svoje pozicije u automobilskoj industriji početkom osamdesetih godina, predsjednik kompanije Rodžer B. Smit (Roger Smith) odlučio je da krene pravcem divrezifikacije. Smit je odlučio da je najbolji način za to da se „udruži "sa EDS korporacijom (Electronic Data System), čiji je vlasnik i osnivač Ros Pero (Ross Perott), američki milijarder, poznat po finansiranju spašavanja američkih talaca iz Irana. Pero je dobio mjesto u poslovodnom odboru GM, ali su stvari ubrzo krenule lošim tokovima. Naime, Pero je bio preduzetnik brzih reakcija, čovjek koji je postizao munjevite poslovne uspjehe. S druge strane, Smit je imao drugi stil: sporiji, sa više razmišljanja i bez velikog rizikovanja. Teško je bilo pokrenuti ogromnu birokratsku mašineriju GM. Na žalost, dva vrsna biznismena nisu mogla zadugo da ostanu zajedno. Pero je smatrao da mnogo toga treba promijeniti u GM - i to što prije. Smit je smatrao da Pero ne razumije poslovnu filozofiju GM. Ubzo je došlo do "razdruživanja“, a Pero je dobio 700 miliona dolara da napusti svoju poziciju u poslovodnom odboru GM. Analitičari GM-a ubrzo su zaključili da su sastanci poslovodnog odbora kompanije mnogo mirniji nego prije, ali se vjerovatno i danas pitaju, da li će GM biti bolji zato što se odrekao usluga jednog od najblistavijih menadžera u SAD.

Koji model organizacione socijalizacije izabrati, da bi ona bila uspješna? Vjerovatno svaki, koji bi „utemeljenje“ tražio u sljedećih šest principa [1]:

1. Obezbjeđenje prvog izazovnog posla.

2. Obezbjeđenje odgovarajuće obuke.

3. Stalno praćenje (i isticanje) uspjeha koji na poslu postiže novi radnik (službenik).

4. Izbor dobrog supervizora koji će se starati o organizacionoj socijalizaciji pripravnika.

5. Kreiranje interesantnog, fleksibilnog i relaksirajućeg programa obuke.

6. Uključenje pripravnika u radnu grupu (tim) sa visokim radnim moralom.

\section{ORGANIZATIONAL SOCIALIZATION AS INTEGRATING FACTOR OF ORGANIZATIONAL CULTURE}

\footnotetext{
Abstract:

In the conditions of market globalization, problems which organizations meet are becoming more complex. In the battle for competitiveness, organizational culture appears as an important factor for the success of the organization. Namely, corporate culture is related to the increasing demands in terms of improved operational efficiency; it is important for defining the new work values, because of the visible tendency of disrespect norms in the process of work (especially in the developed countries whose principles have been related to the Protestant ethics); corporate culture is also related to the phenomenon of losing meaning in the world of work, where the hedonistic values are growing rapidly, and for social disintegration and disorientation, too. One of the conditions for better business operations is the ability of managers to improve the culture in the organization. According to numerous authors socialization is a good way to accomplish this.
}

\section{Key words:}

organizational culture, organizational behaviour, organizational socialization. 